\title{
O 'NOVO' da COVID-19: impactos na saúde mental de profissionais de enfermagem?
}

The novel COVID-19: impacts on nursing professionals' mental health? Lo "NUEVO" de la COVID-19: impactos en la salud mental de profesionales de enfermería

Aline Macêdo Queiroz ${ }^{1}$ iD https://orcid.org/0000-0002-7374-011x

Anderson Reis de Sousa ${ }^{2}$ id https://orcid.org/0000-0001-8534-1960

Wanderson Carneiro Moreira ${ }^{3}$ id https://orcid.org/0000-0003-2474-1949 Maria Do Perpétuo Socorro de Sousa Nóbrega ${ }^{3}$ io hittps://orcid.org/0000-0002-4974-0611

Milena Bitencourt Santos ${ }^{2}$ is https://orcid.org/0000-0003-4137-7915

Laura Jennifer Honorato Barbossa ${ }^{1}$ id https://orcid.org/0000-0002-2313-1201

Larissa de Almeida Rezio ${ }^{4}$ id https://orcid.org/0000-0003-0750-8379

Sonia Regina Zerbetto ${ }^{5}$ is https://orcid.org/0000-0002-2522-1948

Priscila Maria Marcheti ${ }^{6}$ io https://orcid.org/0000-0002-1662-4139

Cíntia Nasi ${ }^{7}$ io https://orcid.org/0000-0002-4322-3701

Elda de Oliveira ${ }^{8}$ io https://orcid.org/0000-0002-9973-0948

\section{Como citar:}

Queiroz AM, Sousa AR, Moreira WC, Nóbrega MP, Santos MB, Barbossa LJ, et al. O 'NOVO'

da COVID-19: impactos na saúde mental

de profissionais de enfermagem?. Acta Paul Enferm. 2021;34:eAPE02523.

DOI

http://dx.doi.org/10.37689/actaape/2021A002523

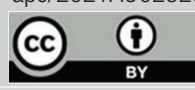

Descritores

Pandemia; Infecções por coronavirus; COVID-19; Saúde mental; Profissionais de Enfermagem

Keywords

Pandemics; Coronavirus infections; COVID-19 Mental health; Nurses practitioners

Descriptores

Pandemias; Infecciones por coronavirus, COVID-19; Salud mental; Enfermeras practicantes

Submetido
9 de Setembro de 2020
Aceito
26 de Março de 2021

\section{Autor correspondente}

Aline Macêdo Queiroz

E-mail: alinemacedo@ufpa.br

\section{Resumo}

Objetivo: Apreender os impactos na saúde mental de profissionais de Enfermagem face às interações com 0 'novo' da pandemia da Covid-19.

Métodos: Recorte qualitativo, da macropesquisa "Estudo VidaMenta/Covid-19", realizado com 719 profissionais de Enfermagem residentes no Brasil. A coleta de dados foi realizada em ambiente virtual com a aplicação da técnica bola de neve. Para a análise metodológica utilizou-se o Discurso do Sujeito Coletivo e para interpretação teórica e filosófica recorreu-se a elementos do Interacionismo Simbólico.

Resultados: 0 discurso coletivo evidenciou que a saúde mental de profissionais de Enfermagem foi afetada pelas: interações com 0 'novo' com elaboração de significados atribuídos à pandemia; interações com 0 cuidado de Enfermagem relacionadas com os atendimentos aos pacientes; e interações com o trabalho demarcadas pelas relações profissionais e institucionais.

Conclusão: Os achados confirmam que há impactos na saúde mental de profissionais de Enfermagem no contexto da pandemia Covid-19 que se manifestam a partir da interação com o 'novo'. Nessa interação trazem o advento de um 'cuidado de Enfermagem pandêmico', permeado por especificidades que emergiram e apresenta uma possibilidade de mudança de paradigma para as diretrizes de formação em Enfermagem, nos avanços tecnológicos de ensino-aprendizagem e na prática profissional.

\section{Abstract}

Objective: To understand mental health impacts on nursing professionals in the face of interactions with the novel COVID-19 pandemic.

Methods: This is a qualitative cut, from the macrosearch "Estudo VidaMenta/Covid-19", carried out with 719 nursing professionals residing in Brazil. Data collection was performed in a virtual environment using the snowball technique. For methodological analysis, the Discourse of the Collective Subject was used and for theoretical and philosophical interpretation, Symbolic Interactionism elements were used.

Results: The collective discourse showed that nursing professionals' mental health was affected by: interactions with the 'new' with the elaboration of meanings attributed to the pandemic; interactions with nursing care related to patient care; interactions with work demarcated by professional and institutional relationships.

\footnotetext{
Faculdade de Enfermagem, Universidade Federal do Pará, Belém, PA, Brasil.

¿Escola de Enfermagem, Universidade Federal da Bahia, Salvador, BA, Brasi.

${ }^{3}$ Escola de Enfermagem, Universidade de São Paulo, São Paulo, SP, Brasil.

${ }^{4}$ Faculdade de Enfermagem, Universidade Federal de Mato Grosso, Cuiabá, MT, Brasil.

${ }^{5}$ Departamento de Enfermagem, Universidade Federal de São Carlos, São Carlos, SP, Brasil.

${ }_{6}^{6}$ Faculdade de Enfermagem, Universidade Federal de Mato Grosso do Sul, Campo Grande, MS, Brasil.

'Escola de Enfermagem, Universidade Federal do Rio Grande do Sul, Porto Alegre, RS, Brasil.

${ }^{8}$ Escola Paulista de Enfermagem, Universidade Federal de São Paulo, São Paulo, SP, Brasil.

Conflitos de interesse: nada a declarar.
} 
Conclusion: The findings confirm that there are impacts on nursing professionals' mental health in the COVID-19 pandemic context that manifest themselves through the interaction with the 'new'. In this interaction, they bring the advent of 'pandemic nursing care', permeated by specificities that have emerged and presents a possibility of changing the paradigm for nursing training guidelines, in technological advances in teaching and learning and in professional practice.

\section{Resumen}

Objetivo: Comprender los impactos en la salud mental de profesionales de enfermería frente a las interacciones cono lo "nuevo" de la pandemia de COVID-19.

Métodos: Recorte cualitativo, de la macroinvestigación "Estudo VidaMenta/Covid-19", realizado con 719 profesionales de enfermería residentes en Brasil. La recolección de datos fue realizada en ambiente virtual con la aplicación de la técnica bola de nieve. Para el análisis metodológico se utilizó el Discurso del Sujeto Colectivo, y para la interpretación teórica y filosófica se recurrió a elementos del Interaccionismo Simbólico.

Resultados: El discurso colectivo evidenció que la salud mental de profesionales de enfermería estuvo afectada por: interacciones con lo "nuevo" con elaboración de significados atribuidos a la pandemia; interacciones con el cuidado de enfermería relacionadas con la atención a pacientes, e interacciones con el trabajo determinadas por las relaciones profesionales e institucionales.

Conclusión: Los resultados confirman que hay impactos en la salud mental de profesionales de enfermería en el contexto de la pandemia de COVID-19, que se manifiestan a partir de la interacción con lo "nuevo". Esta interacción trae consigo el advenimiento de un "cuidado de enfermería pandémico", impregnado de especificidades que surgieron, y presenta una posibilidad de cambio de paradigma de las directrices de formación en enfermería, en los avances tecnológicos de enseñanza-aprendizaje y en la práctica profesional.

\section{Introdução}

A pandemia da COVID-19 é considerada a maior emergência de saúde pública enfrentada pela comunidade internacional em décadas. ${ }^{(1,2)} \mathrm{A}$ rápida e elevada disseminação do SARS-CoV-2 modificou o cotidiano da população e afetou o trabalho em saúde, com expressividade para a Enfermagem, causando repercussóes psicossociais. ${ }^{(3,4)}$

Em caráter danoso a pandemia da COVID-19 provocou até o dia 08 de maio de 2020 a morte de 98 profissionais de Enfermagem. Até esta data já eram mais de 3 mil profissionais infectados pelo SARS-CoV-2, que somados aos casos suspeitos, ultrapassam a marca de 11 mil notificaçóes reportadas ao Conselho Federal de Enfermagem brasileiro e com vasto número de afastamento do trabalho. A partir dos dados emitidos pelo Conselho Federal de Enfermagem brasileiro, o número de profissionais de Enfermagem que morreram no Brasil ultrapassaram países como a Espanha, a Itália e os Estados Unidos. ${ }^{(5,6)}$

Por serem o maior contingente da força de trabalho em saúde e estarem na "linha de frente" da assistência à COVID-19, profissionais de Enfermagem foram postos em evidência, migrando de um status de desvalorização ao de heroi. No entanto, se reconhece o adoecimento mental desses profissionais, com elevação da ansiedade, medo e dor diante da convivência com a morte de pacientes e colegas no ambiente de trabalho, agravado pelo risco elevado de exposição à infecção, de transmissão do vírus para familiares, condições precarizadas de trabalho, reduzida proteção social, insegurança no trabalho e desconhecimento para lidar com o 'novo' e o 'imprevisível'. ${ }^{(7-9)}$

Mediante ao processo de interação social presente no advento e no prolongamento da COVID-19, os profissionais de Enfermagem estão vivenciando significativos impactos na saúde mental. Já tem sido observados comprometimentos na força de trabalho, com reflexos nos anos potenciais perdidos, desordem psíquica, estresse pós-traumático. ${ }^{(10,11)}$ Face a este cenário preocupante, a atenção e vigilância deve ser potencializada por parte de agentes públicos, governantes e gestores, a fim de garantir a proteção à vida e a saúde e estabelecer ações eficazes no enfrentamento dos efeitos deletérios na saúde mental desta categoria. ${ }^{(11)}$

Diante disso, o questionamento condutor deste estudo foi: como profissionais de Enfermagem interagem com o 'novo' da pandemia da COVID-19 e quais são os impactos na saúde mental advindos dessa interação? Assim, o estudo tem como objetivo apreender os impactos na saúde mental de profissionais de Enfermagem face às interaçôes com o 'novo' da pandemia da COVID-19.

\section{Métodos}

Trata-se de recorte qualitativo, de uma macropesquisa intitulada: "Saúde mental de profissionais de enfermagem do Brasil - Estudo VidaMental/ 
Covid-19”, realizado com 719 profissionais de Enfermagem residentes no Brasil. A pesquisa foi realizada em ambiência virtual, por meio de formulário do Google Forms, elaborado e validado previamente por sete pesquisadores com expertise na área e um profissional vinculado ao serviço de atendimento à pessoa com a COVID-19. O questionário foi composto de 41 questóes fechadas sobre a caracterização sociodemográfica/laboral/saúde e, uma questão aberta acerca dos sentimentos diante do contexto da pandemia da COVID-19, a qual foi utilizada para análise neste artigo, a saber: Fale-nos sobre as suas vivências e sentimentos ao longo do contexto da pandemia COVID-19?

A coleta de dados ocorreu entre abril e junho de 2020, pela técnica snowball sampling - bola de neve, a qual possibilitou realizar o recrutamento consecutivo de participantes para o estudo, para o alcance das amostras iniciais e das ondas amostrais subsequentes. Para o recrutamento valeu-se da publicização no Facebook, Instagram, Twitter, WhatsApp e correios eletrônicos. Previamente a análise, os questionamentos foram checados quanto à duplicidade e incompletudes. Do total apreendido, cinco foram descartados pelas razôes anteriores mencionadas. Por se tratar de dados obtidos em ferramentas digitais, preservou-se a identificação dos participantes. Desse modo, nenhum dado pessoal que gerasse a exposição individual foi solicitado. Ademais, aportou-se critérios de segurança e proteção virtual dos dados, a partir do emprego de códigos, zipagem de pastas e manipulação em dispositivos protegidos por senhas.

A amostra foi intencional e adotou-se cinco passos: registro de dados brutos, a imersão nos dados, a alocação dos temas com a construção da grade de saturação, na qual os principais elementos do discurso foram listados e observado a recorrência das informaçôes, como critérios de saturação teórica, em razão do quantitativo elevado de respostas oriundas da pesquisa matriz. Para tanto, empregamos a leitura linha a linha, busca por coocorrências, convergências, complementariedades e densidade teórica dos dados. ${ }^{(12)}$ Faz-se saber que a saturaçáo teórica dos dados ocorreu a partir do recolhimento das respostas apreendidas no mês de junho de 2020. No que tange à seleção da amostra, elegeu- -se como critérios de inclusão: ser profissional de Enfermagem, residente no Brasil, em vivência da pandemia da COVID-19. Os critérios de exclusão foram: se encontrar em viagem internacional e/ou em trânsito entre o Brasil e outros países no período da coleta de dados. Destarte, no tocante à saturação teórica, empregou-se-a no momento de análise dos achados revelados após o processamento junto ao Software IRaMuTeQ ${ }^{\circledR}$, recurso colaborativo da sistematizaçáo dos dados, que identificou a frequência de palavras, processo que foi direcionado pelo método do Discurso do Sujeito Coletivo (DSC).

Ao tomar como base o método do DSC, procedeu-se com a localização das Expressôes Chaves e das Ideias Centrais de uma representação coletiva. ${ }^{(13)}$ Destarte, o emprego do DSC possibilitou reconhecer as categorias analíticas mediante as premissas próprias do método. Além mais, os dados analisados foram interpretados pelos fundamentos do Interacionismo Simbólico (IS), ${ }^{(14)}$ que tem como paradigma as pessoas e sua inserção e interação com/no mundo social. A partir da localização das Ideias Centrais, buscou-se apreender as ancoragens, que foram interpretadas à luz do IS, a partir das suas premissas essenciais.

A categorização está representada no infográfico realizado na ferramenta das Coggle . Para a categorização, tomou-se como base a leitura linha a linha, apreensão das coocorrências, convergências e complementaridades, que foram guiadas pelo método do DSC.

Adotou-se os critérios do COREQ ${ }^{(15)}$ e o estudo atendeu a todas as normas nacionais e internacionais de ética em pesquisa envolvendo seres humanos.

\section{Resultados}

Participaram do estudo profissionais de Enfermagem - a maioria Enfermeiras(os) e Técnicas(os) de Enfermagem, que atuavam na assistência direta $(65,6 \%)$, com tempo de formação profissional médio de 14 anos e residentes nas cinco regióes do Brasil. A maioria eram mulheres $626(87,1 \%)$ e se encontravam com faixa etária média entre 25 a 45 anos. Casadas $292(40,6 \%)$ e de raça/cor autoreferida branca 343 (47,7\%). 
O discurso coletivo evidenciou que a saúde mental de profissionais de Enfermagem foi afetada pelas interaçóes com o 'novo', advindo da pandemia da COVID-19. A representação coletiva dos discursos elaborados dos significados atribuídos pelos participantes aos termos/ palavras foram: pandemia, Coronavírus, COVID-19, exposição, suspeito, pacientes, atendimento, profissionais, instituiçóes, setores, fazer e processo de trabalho, não restritos apenas à pandemia em si, mas tudo que advém do processo histórico das suas interaçóes no cotidiano do trabalho, apresentadas nos discursos-sínteses que se ancoram em suas respectivas idéias centrais.

De acordo com a figura 1, o trabalho de profissionais de Enfermagem tem centralidade em seus

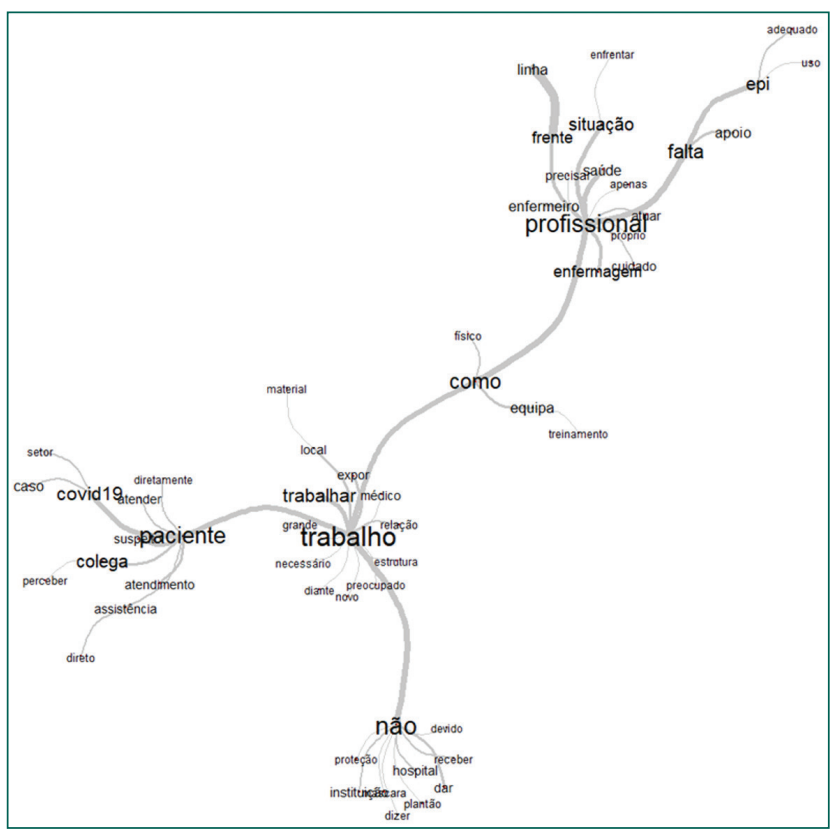

Figura 1. Árvore de Similitude com as palavras mais evocadas pelos profissionais de Enfermagem relatos e se articula com as exigências e necessidades para o exercício do cuidado dos pacientes, bem como expóe as interfaces do "como" o agir profissional se processa no contexto de carências e não proteção da situação pandêmica.

A estrutura da categorização dos achados expressos nos discursos-sínteses e suas Ideias Centrais se encontram representadas na figura 2 .

\section{Discursos-síntese 01: A interação com o 'novo'}

A interação com o contexto pandêmico e da COVID-19 emergiu no discurso coletivo e demonstrou o caráter de especificidade da atuação da Enfermagem no Brasil, não vivenciada neste século. Nesta interação, ao avançar no conhecimento sobre o vírus e a nova doença, profissionais de Enfermagem constataram a complexidade da virulência e vivenciaram a dificuldade de lidar com o 'novo', o que deflagrou sentimentos negativos:

\section{"[...] infelizmente estamos lidando com uma situa-} çâo única, com um vírus novo e, como profissional de saúde na "linha de frente", fico apreensiva(o), assustada (o) e desesperada (o) frente aos novos acontecimentos relacionados a COVID-19. O virus é devastador, sinto insegurança, vulnerabilidade $e$ pequena(o) para enfrentar à COVID-19. Mesmo buscando conhecimento sobre a doença, o contágio e os cuidados a serem desempenhados no trabalho, me sinto impotente." (DSC).

Os significados se constituíram nas interaçóes sociais com os seus pares no ambiente profissional e estão ancorados no medo da 'exposição', decorrente

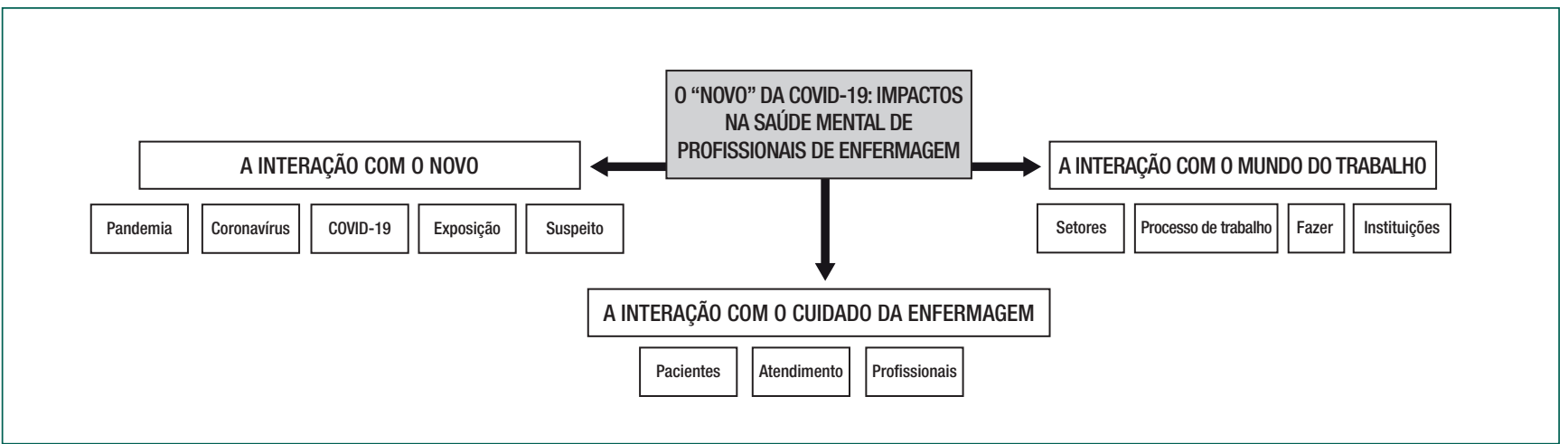

Figura 2. Estruturação das categorias analíticas do Discurso do Sujeito Coletivo do fenômeno investigado 
da insegurança no trabalho, pela ausência de capacitação para lidar com o inédito e, receio da continuidade de desvalor da profissão:

"[...] estou exposta(o) a muitas horas de trabalho junto aos pacientes com a COVID-19. Falta segurança no trabalho e capacitaçóes. Me sinto despreparada, não sabemos como atender pacientes com Covid-19 e se as medidas de proteção estão sendo realizadas de maneira adequada. A pandemia surgiu no ano da valorização da Enfermagem, mas estamos sofrendo sem saber se seremos novamente esquecidos quando tudo passar." (DSC).

A pandemia provocou a adoção de novas atitudes e mudanças de comportamento tanto para proteção do próprio profissional e de sua família, como medidas de contenção econômica:

"[...] eu precisei me isolar em casa, em um quarto separado e ter que adotar cuidados mais rigorosos de higienização antes e após o trabalho. Passei também a tomar medidas de segurança para poder continuar trabalhando. Busquei ajudar as pessoas mais necessitadas, economizar no consumo de água, evitar o desperdicio de alimentos e organizar as finanças." (DSC).

Na interação entre o profissional de Enfermagem e o 'suspeito' de contaminação pela COVID-19, seja paciente ou profissional, construiu-se o imaginário simbólico da pandemia, o qual é permeado por contradiçóes entre medo do contato e satisfação em prestar o cuidado. $\mathrm{O}$ ineditismo do contexto vivenciado pela categoria gera multiplicidade de sensaçóes que revelam o "não dito", expressas em metáforas para nominarem o que não conhecem ou não sabem como descrever:

"[...] a Enfermagem será "alma" da assistência nessa nova situação, tem também me deixado no "fundo do poço", me fazendo sentir um "robô" $e$ um "lixo". Atender pacientes suspeitos e confirmados de COVID-19 gera diversas sensaçôes. De um lado sinto gratidão por estar trabalhando, contribuir profissionalmente. Por outro lado, sinto apreensão, frustração, impotência e raiva por conviver com a incerteza de não saber quem é suspeito para o Coronavirus, sejam os pacientes, colegas de trabalho e até eu mesma(o)." (DSC).

\section{Discursos-síntese 02: A interação com 0 cuidado de Enfermagem}

A interação de profissionais de Enfermagem com os pacientes na realização do cuidado está permeada por sentimentos de medo diante dos que adoecem/ sofrem; pelo desconhecimento da doença, que provoca recusa para o atendimento e excessiva emotividade; pelo receio em esquecer os procedimentos e técnicas de proteção e segurança; por não estarem instrumentalizados para o cuidado e, pelo temor de estarem na "linha de frente" do atendimento aos pacientes:

"[...] a relação direta de estar na "linha de frente" me apavora e gera o temor pelo "novo" e por não saber o que poderá acontecer num futuro próximo. Muitos colegas de trabalho ficaram histéricos, alguns até se negaram a atender os pacientes da COVID-19. Eu atuo na assistência direta aos pacientes, mas sinto medo todos os dias. Medo de esquecer as normas e protocolos para atendimento, medo de adoecer e de contaminar alguém, como os familiares e, o medo de náo dar conta do meu trabalho." (DSC).

Nesse campo simbólico interacional, a relação entre prestar o atendimento aos pacientes com COVID-19 e sentimentos de afliçáo frente à possibilidade de mudar da condição de profissional para paciente, diante do risco da contaminação, da morte e da convalescência de colegas de trabalho, revela situaçôes de sobrecarga emocional e física desses profissionais que prestam cuidado no contexto pandêmico, que privam de realizarem suas necessidades básicas:

"[...] o atendimento envolve uma atividade profissional de elevado contato e exposição e, muitos colegas necessitaram se afastar do trabalho por estarem com a COVID-19. Outros até vieram a falecer, o que gera apreensão e exaustão física 
e emocional. Preocupo com o atendimento dos pacientes com a COVID-19, me dedico intensamente, busco fazer o melhor, mas há momentos que temo adoecer e tornar paciente. Quase nunca posso parar para beber água e usar o sanitário. Fico muitas horas com os EPI, sem ter local adequado para tomar banho após o plantão, realizar a paramentação e desparamentação e ainda lidar com a sobrecarga de trabalho. Tenho pouca confiança nas melhorias para a profissão de Enfermagem." (DSC).

A interação de profissionais de Enfermagem com a população ao prestar atendimento com/na pandemia foi permeada pelo reconhecimento e notoriedade da categoria profissional na produção do cuidado. Entretanto, os relatos apontam também situaçôes de violência, discriminação, estigma e desrespeito ao isolamento social pela população, que dificultam o exercício profissional:

"[...] o atendimento aos pacientes fica comprometido pois tenho vivido momentos de angústia. Sofro agressóes. Presencio a falta de empatia de muitos pacientes e familiares, que náo reconhecem o desafio enfrentado. A convivência com a violência tem sido mais próximalfrequente com a pandemia. As pessoas reagem negativamente por trabalharmos com a COVID-19. Emociono com o reconhecimento, mas entristeço com a discriminação, falta de amor, compaixão e o não cumprimento do isolamento social, o que torna o trabalho de Enfermagem ainda mais difícil." (DSC).

Nas interações de profissionais de Enfermagem com o paciente ao prestarem atendimento/assistência durante o contexto pandêmico, há satisfação e sensação de dever cumprido, além de adoção de novos modos de trabalho:

“[...] há também o sentimento de prazer, de dever cumprido, em poder prestar assistência aos pacientes que tanto precisam e contam comigo. Agora eu também atuo com o teleatendimento, o que é novo, mas que estou tendo contato." (DSC).

\section{Discursos-síntese 03: A interação com o cotidiano do trabalho}

Quando as situaçóes adversas geradas pela pandemia passam a tecer influências sobre o cuidado de profissionais de Enfermagem, especialmente no âmbito da relação da categoria junto às instituições de saúde e setores de trabalho, relacionadas à ingerência e irresponsabilidade organizacional que não garantem a segurança profissional para prestarem cuidado com qualidade, emergem sentimentos de insatisfação pela ausência de acolhimento/apoio emocional e psicossocial:

"[...] mesmo a transformação provocada pela pandemia tive que lidar com a falta de máscara, como atuar na "linha de frente" com essas condiçóes? Falta gerência no trabalho, pois além de atender, eu ainda tenho que treinar funcionários que nunca trabalharam na assistência e isso me sobrecarrega e afeta a qualidade do atendimento. Irresponsabilidade para lidar com o número elevado de casos da doença, e falta de apoio psicológico." (DSC).

A relação com os setores de trabalho está permeada por mudanças inesperadas de postos de trabalho para o desempenho de diferentes e novas atribuiçôes, reapropriação célere de novos conhecimentos, o que transformou as rotinas de trabalho, ao priorizar outras demandas advindas da COVID-19:

"[...] precisei cuidar de pacientes graves e com necessidade de internação em Unidade de Terapia Intensiva, mesmo sem ter sido treinada(o) e nunca ter trabalhado naquele setor. Os treinamentos que ocorreram foram rápidos e superficiais e muitas pessoas recém admitidas foram convocadas para atuar. Preciso lidar com os desafios do trabalho em equipe, com a chegada de inumeros pacientes com a COVID-19, gerando lacunas no atendimento. Tive que priorizar o atendimento de pacientes com situaçóes criticas. Houve transformaçóes das rotinas de trabalho, escalas de serviço e distanciamento social." (DSC).

Ao analisar simbolicamente a interação de profissionais de Enfermagem junto aos setores e às con- 
dições de trabalho das quais são submetidos com a COVID-19, intensificaram problemáticas laborais. A categoria profissional conviveu com desarranjos, inadaptaçôes, alteração de rotinas, escassez de materiais, sobrecarga de trabalho e condiçóes insalubres, aspectos que desencadearam insegurança e impactaram no bem-estar psicossocial:

"[...] tive que lidar com a insalubridade, exposição elevada à contaminação pelo Coronavirus, e aumento do tempo de permanência no trabalho. Esses problemas institucionais não são novos, o 'novo' é a chegada da COVID-19 que intensificou as falta de condiçôes dignas de trabalho e não atenção para os profissionais. É um cenário novo e difícil. É humanamente impossivel um profissional de Enfermagem sozinho, atender vinte pacientes, sem uma equipe completa e com insuficiência de materiais. Me aflige, gera impotência, insatisfação e não há reconhecimento financeiro e social." (DSC).

A insegurança no ambiente de trabalho provocada pela pandemia trouxe sentimentos de ansiedade, angústia, conflitos de decisão, desesperança, insatisfação e vivência constante do medo, que muitas vezes não são valorizados pelos próprios pares:

"[...] o ambiente de trabalho se transformou em local de medo da contaminação, que "ronda" $e$ preocupa a todo instante. Estamos em risco, não há testagem. Há angústia, insegurança e medo. Tenho sentido ataques de ansiedade e depressão, mas escondo. Isso tem contribuido para um "quadro" de medo e pânico no trabalho. Os comentários negativos vindo dos próprios profissionais, abala, desanima e desencoraja. Quando necessito contar com um apoio psicológico, sou taxada(o) como louca(o), principalmente por parte das coordenaçóes, o que faz me sentir um "lixo"”. (DSC).

\section{Discussão}

Este estudo apresenta como limitação o fato da coleta de dados ter sido conduzida virtualmente, o que impossibilitou empregar mais questóes que norteassem o aprofundamento dos significados do objeto investigado. Contudo, apreendeu-se a relação estabelecida pelos profissionais de Enfermagem na interação com o 'novo' da Pandemia, os significados atribuídos à nova realidade de trabalho constituídos nas interaçóes com os pacientes, a COVID-19 e os seus pares e as evidências de impactos à saúde mental dessa categoria inserida em um diferente mundo social.

Os achados revelam os impactos na saúde mental dos profissionais de Enfermagem face à interação com o medo do 'novo' da pandemia. Elucidou-se que os significados e as açóes sociais estão permeadas pelo medo. Reconheceu-se o desafio no enfrentamento profissional do desconhecido e a deflagração de sinais ansiogênicos e depressivos. Localizouse fenômenos interacionais que estão compondo o novo cenário pandêmico e as suas influências frente ao sofrimento profissional.

Essas revelaçóes são corroboradas com a literatura, ${ }^{(3,4,13,14)}$ maior atenção e vigilância deve ser direcionada por parte de gestores, coordenadores, educadores em serviço, equipes de suporte psicossocial para com as profissionais de Enfermagem, que estão intimamente lidando com os novos contextos emergidos com a pandemia da Covid-19. Ao evidenciar a interaçáo com o 'novo', notou-se que a significação que os profissionais atribuíram, ainda que se pareçam individuais, e particulares à dimensão do self, está a ocorrer mediante as inter-relaçóes e interaçóes com os repertórios pregressos e com os fenômenos novos. ${ }^{(12)}$ Desse modo, importa atentar para os impactos provocados pelas interaçóes com fenômenos novos e provocadores de desarranjos à situação de saúde mental dos profissionais de Enfermagem face ao fazer no coletivo do trabalho.

Quando profissionais de Enfermagem são confrontados com o 'novo' da pandemia, são conduzidos a se deslocarem de um lugar comum e interagirem $^{(12)}$ com o contexto da COVID-19. Na interação profissional com o 'novo' cuidado de Enfermagem, significados e sentidos foram transversalizados pelas ambiguidades que marcam a posição de exercer a profissão e o estar vulnerável, o que provoca impactos diretos e contínuos na saúde mental. Os profissionais de enfermagem, enquanto atores sociais, em dada interação com o 'novo', expressam as "atividades encobertas" e que estão presentes no "comporta- 
mento externo", simbolizadas por fenômenos como a "exposição", "suspeito" e "paciente", mobilizando os impactos à saúde mental desses profissionais. ${ }^{(12)}$

A alta transmissibilidade da doença e a urgência em adotar medidas que promovam a segurança de profissionais que realizam assistência, os colocam em um cenário que integra maior suporte de atendimento, traduzido em maior exposição e elevado risco de contaminação. ${ }^{(15,16)}$ Neste sentido, profissionais vivenciam em níveis elevados e constantes as sensaçóes de medo, incerteza e insegurança na realização do cuidado. Os impactos na saúde mental de profissionais de Enfermagem revelados, em convergência com as premissas do IS, ${ }^{(12)}$ parecem estar permeados por particularidades, e/ou que elucidam que os mesmos ocorrem restritos ao ambiente de trabalho assistencial. $\mathrm{O}$ olhar vigilante às particularidades existentes na interação com o 'novo' do contexto pandêmico, como os evidenciados neste estudo, permitirá a adoção de medidas coletivas que sejam eficazes na proteção da saúde mental dos profissionais de Enfermagem.

No âmbito da interação com o cotidiano do trabalho, no envolvimento com 'novo', com as instituições, setores, com o fazer e com o processo de trabalho, o discurso revelou que os profissionais de Enfermagem as degradaçóes pré-existentes na profissão, de baixa valorização e precariedade foram fortemente impactados por novas degradaçóes, que se sobrepóem e por vezes descaracterizam o seu fazer, como reforçados na literatura. ${ }^{(5,15,16)}$ Realidade que os expóem a condições de trabalho ainda mais impróprias, e retiram-lhes a garantia do alcance do bem-estar no trabalho e consequentemente o bem-estar psicológico, haja visto que a literatura científica já têm apontado os impactos secundários, como o TEPT. ${ }^{(3,5)}$

O lugar simbólico pode ser reconhecido nos objetos, nas linguagens, nos símbolos, como vistos nos fenômenos "setores", "processo de trabalho", que recebe influências dos processos interpretativos, nos desdobramentos da tecitura social, ${ }^{(12)}$ como, por exemplo, a comunicação midiática sobre a pandemia e as relaçóes com o fazer da Enfermagem. Destaca-se as denúncias feitas pela categoria que evidenciam os desgastantes, as condiçóes de trabalho e a potencialização do esgotamento físico e mental vivenciados. ${ }^{(16)}$
A concretude dos dados discursivos evidenciados neste estudo expuseram a produção de sofrimento vivenciados pela categoria profissional de Enfermagem. Os significados atribuídos pela categoria investigada explicitam os efeitos deletérios ao bem-estar psicossocial e no trabalho e das repercussóes negativas em distintas dimensôes da vida, o que carece de atenção, vigilância, monitoramento e a criação de estratégias eficazes que sejam passíveis de garantir a proteção da integridade humana e da manutenção da qualidade de vida e da situação/condição de saúde desses profissionais. ${ }^{(10,11)}$ Face a esse cenário, um cuidado integrativo em Enfermagem que considere as dimensóes simbólicas no contexto social merece ser considerada. ${ }^{(17,19)}$ Programas de promoção do cuidado em saúde mental necessitam ser implementados e fortalecidos. $\mathrm{O}$ rastreamento e monitoramento dos agravos na saúde mental dos profissionais de Enfermagem precisam ser efetivados.

Conhecer de maneira acurada o 'novo' da pandemia da COVID-19 promove mais possibilidades de direcionamentos para a condução da prática de Enfermagem, tal como do estabelecimento das açóes de proteção no âmbito do trabalho. Além do mais, possibilita guiar qualitativamente a instrumentalização dos profissionais de Enfermagem para adotarem as estratégias de enfrentamento mais adequadas, face à sua disposição, acesso e possibilidades. Vale destacar, que este estudo chama a atenção para a necessidade de apoiar a categoria de Enfermagem e estabelecer estratégias para ampliar a atuação dessas profissionais.

Ressalta-se ainda que os achados trazem o advento de um 'cuidado de Enfermagem pandêmico', permeado por especificidades que emergiram com o 'novo' da COVID-19, e apresenta uma possibilidade mudança de paradigma para as diretrizes de formação em Enfermagem, nos avanços tecnológicos de ensino-aprendizagem e prática profissional, na regulação ética e legal da profissão. Inclui-se também na reorganização do processo de trabalho em Enfermagem, e estruturação institucional, surgimento de novas investigaçôes clínicas, formulaçôes diagnósticas e de linhas de pesquisa específicas.

As contribuiçóes deste estudo para a prática se expressam através da proposição do avanço do conhecimento científico de Enfermagem e o seu dire- 
cionamento no âmbito da saúde mental, que direcionam para um novo olhar sobre as possibilidades de implementação de açóes que minimizem os impactos, garantam a proteção, integridade e dignidade humana e a melhoria das condiçóes de trabalho, ainda mais emergenciais neste cenário.

\section{Conclusão}

O discurso coletivo dos profissionais de Enfermagem evidenciou que há impactos na saúde mental provocados pela interação com o 'novo' apresentado pela pandemia da COVID-19 e estão constituídos de elementos que se deram na interação, e que também se sobrepõem aos já vivenciados anteriormente, a saber: o 'novo', o coronavírus, a COVID-19, a deflagração de sentimentos negativos, as vulnerabilidades no fazer profissional - fragilidades na instrumentalização/ execução técnica, risco de contaminação, exposição por estarem na "linha de frente, falhas na segurança, aproximaçáo com a morte, medo, a precarização do trabalho e a falta de acolhimento/apoio emocional e psicossocial. Os achados alertam para a necessidade de apoiar a categoria no que se refere às questóes psicossociais, à formação, aos avanços tecnológicos de ensino-aprendizagem e prática profissional, à regulação ética/legal, a organização do trabalho, estratégias para ampliar a atuação qualificada e protegida em cenários críticos e emergenciais como de uma pandemia.

\section{Colaborações}

Queiroz AM, Sousa AR, Moreira WC, Nóbrega MPSS, Santos MB, Barbossa LJH, Rezio LA, Zerbetto SR, Marcheti PM, Nasi C e Oliveira E colaboraram com a concepção, redação, revisão crítica relevante do conteúdo intelectual e aprovação da versão final do artigo.

\section{Referências}

1. World Health Organization (WHO). Statement on the second meeting of the international health regulations (2005) Emergency Committee regarding the outbreak of novel coronavirus (2019-nCoV). Published January 30, 2020. Geneva: WHO; 2020 [cited 2020 July 19]. Available from: https:// www.who.int/news-room/detail/30-01-2020-statement-on-the-secondmeeting-of-the-international-health-regulations-(2005)-emergencycommittee-regarding-the-outbreak-of-novel-coronavirus-(2019-ncov)

2. Mizumoto K, Chowell G. Transmission potential of the novel coronavirus (COVID-19) onboard the diamond Princess Cruises Ship, 2020. Infect Dis Model. 2020;5:264-70.

3. Ornell F, Schuch JB, Sordi AO, Kessler FH. "Pandemic fear" and COVID-19: mental health burden and strategies [editorial]. Braz J Psychiatry. 2020;42(3):232-5.

4. Gold JA. Covid-19: adverse mental health outcomes for healthcare workers [editorial]. BMJ. 2020;369:m1815.

5. Conselho Federal de Enfermagem (COFEN). Brasil ultrapassa EUA em mortes de profissionais de Enfermagem por Covid-19. Brasília (DF): COFEN; 2020 [citado 2020 Out 10]. Disponível em: http://www. cofen.gov.br/brasil-ultrapassa-eua-em-mortes-de-profissionais-deenfermagem-por-covid-19_79624.html

6. Conselho Federal de Enfermagem (COFEN). Brasil perdeu mais profissionais de Enfermagem que Itália e Espanha juntas. Brasília (DF): COFEN; 2020 [citado 2020 Out 10]. Disponível em: http://www.cofen. gov.br/brasil-perdeu-mais-profissionais-de-enfermagem-para-covid19-do-que-italia-e-espanha-juntas_79563.html

7. Moreira WC, Sousa AR, Nóbrega MP. Mental illness in the general population and health professionals during COVID-19: a scoping review. Texto Contexto Enferm. 2020;29:e20200215.

8. Souza LP, Souza AG. Enfermagem brasileira na linha de frente contra 0 novo Coronavírus: quem cuidará de quem cuida? J Nurs Health. 2020;10(Esp.):e20104005.

9. Medeiros EA. Health professionals fight against COVID-19 [Editorial]. Acta Paul Enferm. 2020;33:e-EDT20200003.

10. Fernandes MA, Ribeiro AA. Salud mental y estrés ocupacional en trabajadores de la salud a la primera línea de la pandemia de COVID-19. Rev Cuidarte. 2020;11(2):e1222.

11. Silva DA, Pimentel RF, Merces MC. Covid-19 and the pandemic of fear: reflections on mental health. Rev Saude Publica. 2020;54:46.

12. Nascimento LC, Souza TV, Oliveiral IC, Moraes JR, Aguiar RC, Silva LF. Theoretical saturation in qualitative research: an experience report in interview with schoolchildren. Rev Bras Enferm. 2018;71(1):243-8.

13. Lefevre F, Lefevre AM, Marques MC. Discurso do sujeito coletivo, complexidade e auto-organização. Ciênc Saúde Coletiva. 2009;14(4):1193-204.

14. Blumer H. Symbolic interacionism: perspective and method. USA: University of California Press; 1986.

15. Pinto IF, Campos CJ, Siqueira C. Investigação qualitativa: perspetiva geral e importância para as ciências da nutrição. Acta Port Nutr. 2018;(14):30-4. Review.

16. Dal'Bosco EB, Floriano LS, Skupien SV, Arcaro G, Martins AR, Anselmo AC. Mental health of nursing in coping with COVID-19 at a regional university hospital. Rev Bras Enferm. 2020;73(Suppl 2):e20200434.

17. Silva FV. Nursing to combat the COVID-19 pandemic. Rev Bras Enferm. 2020;73(Suppl 2):e2020sup2.

18. Sant'Ana G, Imoto AM, Amorim FF, Taminato M, Peccin MS, Santana LA, et al. Infection and death in healthcare workers due to COVID-19: a systematic review. Acta Paul Enferm. 2020;33:eAPE20200107.

19. Lopes $\mathrm{CH}$, Jorge MS. Interacionismo simbólico e a possibilidade para o cuidar interativo em enfermagem. Rev Esc Enferm USP. 2005;39(1):103-8. 


\section{Errata}

No artigo publicado na Acta Paul Enferm. 2021; 34:eAPE02523, Queiroz AM, Sousa AR, Moreira WC, Nóbrega MP, Santos MB, Barbossa LJ, et al; "O 'NOVO' da COVID-19: impactos na saúde mental de profissionais de enfermagem?", os autores solicitaram publicar a seguinte errata:

\section{Agradecimentos}

Ao Conselho Nacional de Desenvolvimento Científico e Tecnológico (CNPq), Ministério da Ciência, Tecnologia, Inovaçôes e Comunicaçôes (MCTIC) e ao Ministério da Saúde (MS). Chamada MCTIC/CNPq/FNDCT/MS/SCTIE/ Decit no 07/2020 - Pesquisas para enfrentamento da COVID-19, suas consequências e outras síndromes respiratórias agudas graves, pelo apoio financeiro, Processo no 4011002020.

\section{Como citar:}

Queiroz AM, Sousa AR, Moreira WC, Nóbrega MP, Santos MB, Barbossa LJ, et al. 0 'NOVO' da COVID-19: impactos na saúde mental de profissionais de enfermagem?. Acta Paul Enferm. 2021;34:eAPE02523. Errata in Acta Paul Enferm. 2021;34:e-APE2021ER2.

D0l: https://doi.org/10.37689/acta-ape/2021errata2

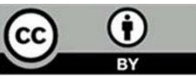

